\title{
Práxis e educação em Gramsci
}

Maria das Graças de Almeida Baptista

Professora da Universidade Federal da Paraíba

\section{Resumo}

O presente trabalho tem por objetivo apontar a práxis como condição pedagógica necessária à educação em Gramsci. Nesse sentido e à luz do referencial gramsciano, busca-se analisar algumas das contradições constitutivas do fazer educativo e ressaltar a práxis na superação dessas contradições, situando a Universidade como lócus privilegiado de construção dessa condição pedagógica.

Palavras-chave: Educação; Práxis; Universidade.

\section{Resumen}

El presente trabajo tiene por objetivo mostrar la praxis como condición pedagógica necesaria a la educación en Gramsci. En ese sentido y a la luz del referencial gramsciano, se busca analizar algunas de las contradiciones constitutivas del hacer educativo y resaltar la praxis en la superación de dichas contradiciones, situando la Universidad como lócus privilegiado de construcción de esa condición pedagógica.

Palabras claves: Educación; Praxis; Universidad. 
definição comumente aceita de Gramsci como teórico da
superestrutura constitui um esvaziamento e uma tentativa de
afastá-lo do materialismo histórico e dialético e do próprio Marx. Entretanto, Gramsci sem abandonar o materialismo em Marx, a determinação econômica e a luta de classes, aprofunda-os na análise acerca da relação infra e superestrutura, desenvolvendo uma filosofia da práxis ${ }^{1}$ em toda a sua plenitude.

A obra de Gramsci, escrita antes, durante e após a Revolução de Outubro de 1917, é marcada pela certeza de uma sociedade socialista vir a se tornar uma realidade também na Itália. A forma de como conseguir chegar a essa sociedade, uma verdadeira estratégia revolucionária, foi o que inspirou seus escritos.

A educação na concepção gramsciana, portanto, só poderia estar voltada para a transformação da concepção do mundo dos sujeitos, através de uma filosofia capaz de abalar as "fortificações", de transformar as mentalidades e de permitir a elevação cultural, ou seja, a filosofia da práxis!

O presente trabalho tem por objetivo, e sem a pretensão de esgotar, apontar a práxis como condição pedagógica necessária à educação em Gramsci. Nesse sentido e à luz do referencial gramsciano, busca-se analisar algumas das contradições constitutivas do fazer educativo e ressaltar a práxis na superação dessas contradições, situando a Universidade como lócus privilegiado de construção dessa condição pedagógica.

\section{O materialismo em Gramsci}

Marx (1978), em $O$ Capital, afirma que a estrutura econômica determina o perfil de uma sociedade e aponta a existência de uma superestrutura dialeticamente necessária e indispensável à dominação e à direção de uma classe sobre a outra, enfim, à manutenção dessa estrutura.

\footnotetext{
1 A utilização do conceito filosofia da práxis, além de evitar a censura aos escritos no Cárcere, reafirma a importância atribuída por Gramsci ao materialismo histórico e dialético, enquanto filosofia da ação consciente dos sujeitos protagonistas no mundo.
} 
Assim, as diferentes idéias e instituições políticas, em diferentes períodos da história da sociedade, se explicam pelas diversas condições da vida material da sociedade das quais são um reflexo. Essas condições têm como força principal o modo de produção dos bens materiais: "o modo de produção da vida material condiciona o processo em geral de vida social, político e espiritual" 2 .

A diferença entre o materialismo e as outras filosofias assenta-se, por um lado, na análise da determinação, se da consciência (pensamento ou idéia) sobre a realidade (as coisas são cópia das idéias); se da realidade sobre a consciência (o movimento do real se reflete na consciência ou no cérebro do homem). Enfim, se a idéia cria a realidade e a realidade só existe a partir da ação do homem, metafísica e idealmente como em Hegel e o idealismo, ou se é o ser social que cria a consciência, como aponta o materialismo.

Por outro lado, na afirmação de Marx de que a dialética tem origem na matéria, na natureza, na realidade, que é contraditória. A contradição é, portanto, a base da dialética marxiana: compreender o real significa compreendê-lo através do movimento contraditório dos fenômenos e sua essência, inclusive da consciência, dando-lhes um caráter provisório e superável.

A contradição é, para o marxismo, a categoria que melhor possibilita compreender a sociedade, e nela, todo o universo do trabalho humano, da atividade humana, e que as relações com o mundo e com os outros homens são determinadas pela realidade em seu devir. Nas sociedades capitalistas, as contradições têm como base a luta de classes e é através da exploração e da dominação que a totalidade fica impossibilitada de aparecer como algo articulado.

A mudança, nesse sentido, é inerente à contradição, na medida em que a contradição é destruidora e criadora. A realidade, na sua dinâmica de constante movimento e superação, é sempre esta tensão entre a realidade (uma possibilidade realizada) e a possibilidade (realidade potencial), e é

${ }^{2}$ Ibid., p. 130. 
esse movimento que torna possível o novo. Negar a contradição no movimento histórico é falsear o real, é representá-lo como estático: "é naturalizar o histórico pela conversão em permanente do que não é senão passageiro" (CURY, 1986, p. 43).

Gramsci (1995, p. 263), sem abandonar o papel determinante e dominante da infra-estrutura econômica e a luta de classes presentes no materialismo histórico e dialético em Marx, e considerando o contexto histórico de sua época, acentua a relação dialética entre a estrutura econômica e a superestrutura.

Nesse sentido, aponta que o desenvolvimento de uma classe depende tanto de uma formação "no terreno econômico [quanto do] desenvolvimento paralelo nos terrenos ideológico, jurídico, religioso, intelectual e filosófico" (GRAMSCI, 1989, p. 49), necessário a uma guerra de posição que exige uma hegemonia ${ }^{3}$ e uma reorganização permanente de forma a manter essa hegemonia.

Em Gramsci, sustenta Buci-Glucksmann (1990, p. 93; 104), a relação entre a ideologia (as idéias) e a estrutura econômica está no fato de que a função hegemônica de classe, as práticas ideológicas aparecem desde o aparelho de produção, a fábrica, integrando um sistema social. Logo, Gramsci, assim como Marx, afirma que é a realidade social (em sua infraestrutura produtiva) que cria as ideologias e não as ideologias (a superestrutura) que criam a realidade social.

A ideologia, para a filosofia da práxis, é "todo o conjunto da superestrutura" e é no terreno da superestrutura (das ideologias) que os homens tomam consciência da sua posição social. A própria filosofia da práxis, enquanto superestrutura, "é o terreno no qual determinados grupos sociais tomam consciência do próprio ser social, da própria força, das próprias tarefas, do próprio devenir”. Contudo, esse conjunto complexo das superestruturas é "contraditório e discordante", uma vez que reflete "o

\footnotetext{
${ }^{3}$ Apesar de Anderson (1986) apontar que os conceitos de Estado, sociedade política e sociedade civil passam por três versões nos Cadernos do Cárcere, essas "antinomias" permanecem imprescindíveis seja para a explicação de sua gênese, seja para a compreensão do papel dessas instâncias nas sociedades capitalistas contemporâneas.
} 
conjunto das relações sociais de produção", também contraditório (GRAMSCI, 1995, p. 262; 270; 52).

A compreensão da relação ideologia e fatores econômicos passa dialeticamente por um dos conceitos chaves do pensamento gramsciano, o de "bloco histórico" " O bloco histórico é formado por uma estrutura social (as classes diretamente relacionadas às forças produtivas) e uma superestrutura ideológica e política. Uma classe que se torne dominante exerce um poder hegemônico sobre a outra, através das relações sociais de produção no nível econômico e de uma "hegemonia" ideológica e política no nível da superestrutura ${ }^{5}$.

Gramsci (1989, p. 10-11) identifica dois planos na superestrutura: o da "sociedade civil" e o da "sociedade política". A princípio, a sociedade civil é analisada como o conjunto dos organismos chamados de "privados" (igrejas, escolas, sindicatos), cuja função é a hegemonia exercida pelo grupo dirigente sobre o conjunto do corpo social (consentimento), e a sociedade política, Estado ou governo (exército, polícia, administração, burocracia), cuja função é a dominação direta ou comando exercido pelo Estado e o poder jurídico (coerção).

No cárcere, amplia o conceito de Estado, Estado integral, de modo que, segundo Buci-Glucksmann (1990, p. 128; 317) este passa a envolver tanto as funções da sociedade política (coercitiva e econômica através do aparelho de Estado), sentido estrito, quanto as da sociedade civil ("papel adaptativo-educativo", hegemônico, adequando o aparelho produtivo à "moralidade" das massas populares), sentido amplo: "não compreender o Estado no sentido integral significa subestimar o adversário no plano político e na arte militar”.

A ampliação da concepção de Estado pressupõe a ampliação do aparelho de Estado, o "aparelho de governo, também o aparelho 'privado'

\footnotetext{
${ }^{4}$ Esse conceito surge com G. Sorel (1847-1922), mas é ampliado por Gramsci. A esse respeito ver Gramsci (1995, p. 263) e Simionatto (2004, p. 41).

${ }^{5}$ Ibid., p. 52.
} 
de hegemonia ou sociedade civil" (GRAMSCI, 2000, p. 254-255), e conduz, necessariamente, à ampliação do conceito de intelectual.

Gramsci (1989, p. 3-4) passa a definir como intelectuais os grupos sociais que, apesar de não formarem uma classe, operam no nível superestrutural e têm por função organizar a hegemonia de um grupo, incluindo nesse grupo os produtores de ideologia, os intelectuais modernos, técnicos, engenheiros, os funcionários de Estado, os organizadores da cultura, os dirigentes de um partido.

O lugar do intelectual não deriva somente das superestruturas, mas também do aparelho de produção. Os intelectuais dão "homogeneidade e consciência da própria função" no campo econômico, no político e no social, ao grupo social que os criou, e são os "comissários" do grupo hegemônico, exercendo "funções subalternas da hegemonia social e governo político" e assegurando a expansão dos diferentes aparelhos de hegemonia da classe dominante ${ }^{6}$.

Entretanto, Gramsci ${ }^{7}$ defende que, nas sociedades capitalistas, o proletariado, assim como a burguesia, deve criar seus próprios intelectuais orgânicos ${ }^{8}$, e adverte que os intelectuais representantes da classe dominante podem suscitar uma atração ("transformismo") nas demais camadas de intelectuais, levando à criação de um "bloco ideológico" ou intelectual, como forma de anular a tentativa de sobrevivência dos grupos rivais e da antiga classe dirigente (BUCI-GLUCKSMANN, 1990, p. 52).

Em Gramsci, entretanto, a hegemonia é em si contraditória, uma vez que se estabelece um consenso sobre o conjunto da sociedade. Logo, quanto mais uma classe é hegemônica, maior possibilidade ela dá às classes

\footnotetext{
${ }^{6}$ Ibid., p. 3; 11.

${ }^{7}$ Ibid., p. 139; 146.

${ }^{8} \mathrm{Na}$ burguesia, o intelectual desempenha um papel direto na constituição de classe; no proletariado, desempenha um papel essencial na organização política de classe. No artigo Para uma renovação do Partido Socialista, Gramsci desenvolve uma forte crítica ao PSI (Partido Socialista Italiano) quanto à sua representatividade junto ao operariado (Cronologia da vida).
} 
adversárias de "se organizarem e de se constituírem em força política autônoma", o que torna os efeitos da hegemonia contraditórios ${ }^{9}$.

Vale salientar que a hegemonia que nasce na fábrica não pode existir sem hegemonia fora da fábrica. A hegemonia na fábrica foi acompanhada de um sistema crescente de limitações ideológicas, uma "moral dos produtores capitalistas" (puritanismo, familiarismo, sexualismo), que serviu de cimento ideológico para a função produtiva ${ }^{10}$. No sistema capitalista, afirma Cury (1986, p. 47; 29), essa construção ideológica tende a assegurar a exploração e a divisão de classes e a negá-la através “de um discurso pretensamente universal, igualitário, e, portanto, falsamente idêntico e homogêneo".

Nesse sentido, como a classe subalterna pode vir a se tornar hegemônica, em uma sociedade de classes? Compreender a concepção do mundo dos sujeitos, no conjunto das relações sociais, entre elas a educação, possibilita compreender o movimento do real, suas contradições, e abrir espaço para a superação dessas contradições e do próprio real.

\section{A educação em Gramsci}

Para que se possa compreender a abrangência do pensamento gramsciano acerca do conceito educação, torna-se necessário compreender tanto o papel que a educação desempenha no nível de uma direção política que permita a elevação cultural de um grupo ou de uma classe, quanto o papel que desempenham as organizações culturais e políticas, "aparelhos de hegemonia" (partidos, escolas ${ }^{11}$, igrejas, jornais, revistas), na construção e manutenção de uma concepção do mundo.

\footnotetext{
${ }^{9}$.Ibid., p. 81-82.

${ }^{10}$ A esse respeito ver Gramsci (2000).

${ }^{11}$ Para Jesus (2005, p. 117), a escola em Gramsci não se restringe à instituição escolar, mas sofre uma ampliação, como ocorre com os conceitos de Estado e de intelectual, e passa a ser definida como "toda a organização que desenvolve cultura".
} 
O problema da relação entre educação e sociedade norteia as reflexões de Gramsci, e esta relação se define na relação entre reforma intelectual (formação do homem novo, partícipe ativo na construção de um novo modelo de sociedade, a socialista) e reforma econômica ("revolução proletária" como fonte de inspiração). Nesse sentido, vale salientar a importância atribuída por Gramsci à ideologia, enquanto conceito central de uma reforma ou "luta" cultural, de uma hegemonia política, no seio da sociedade capitalista, imprescindível a uma guerra de posição.

Nos Cadernos do Cárcere, Gramsci aprofunda a análise marxiana sobre a ideologia e desenvolve uma teoria sobre a sua materialidade e o seu modo de inserção nos aparelhos de hegemonia. Gramsci (1995, p. 16) define ideologia como "uma concepção do mundo, que se manifesta implicitamente na arte, no direito, na atividade econômica em todas as manifestações de vida individuais e coletivas". A ideologia faz com que os sujeitos pertençam a um determinado grupo, cujo modo de pensar e de agir pode ser compartilhado.

Na filosofia gramsciana, o estágio mais elaborado de ideologia é a filosofia, que tem sido a expressão cultural da classe dominante, possibilitando que influencie a concepção de mundo e a vida de todas as camadas sociais. Este é o papel essencial da filosofia no bloco ideológico. O senso comum é um "amálgama" de diversas ideologias tradicionais e da ideologia da classe dirigente, é uma concepção fragmentada, incoerente, inconsequente. O senso comum é o tipo de concepção absorvida "pelos vários ambientes sociais e culturais", sem disso ter-se uma consciência crítica $^{12}$.

O "bom senso" é outro tipo de concepção do mundo que superou o senso comum, elaborada de forma crítica e consciente, ainda que dentro de limites objetivos restritos, e que participa ativamente e conscientemente na "produção da história do mundo".

Vale salientar que, mesmo os indivíduos não atingindo o bom senso, eles participam da história. Entretanto, é somente através da formação de

${ }^{12}$ Ibid., p.14. 
uma concepção do mundo, crítica e consciente, que o sujeito compreende a sua posição no grupo social e se compreende enquanto protagonista na produção da história. A formação dessa concepção estaria ligada ao trabalho, à vida e à ciência. Daí o papel fundamental que a educação (em sentido amplo e incluindo a escola) desempenha nessa formação.

A elevação política de um grupo social implica, segundo Gramsci (1995, p. 14; 36), trabalhar na construção de uma nova filosofia, ou seja, definir sua própria filosofia e combater o senso comum, visando à formação de uma nova concepção do mundo, mais unitária e autônoma, em todos os aspectos da existência. Um trabalho filosófico que deve ser concebido como luta cultural.

A filosofia da práxis, segundo Gramsci, tem papel fundamental nesse processo, pois exige clareza sobre os problemas filosóficos, jurídicos, religiosos e morais, o que torna necessária uma luta de hegemonias políticas, nos campos da ética e da política, até se atingir uma "elaboração superior da própria concepção do real: a consciência de fazer parte de uma determinada força hegemônica, a consciência política, é a primeira fase de uma ulterior e progressiva autoconsciência, na qual teoria e prática finalmente se unificam". A filosofia da práxis implica, portanto, "polêmica com as filosofias tradicionais" $" 13$.

Esse aperfeiçoamento da consciência é, segundo Vázquez (1968, p. 12), a própria história do pensamento humano, é a história da passagem de uma consciência ingênua ou empírica da práxis à consciência filosófica que capta sua verdade, uma verdade em constante movimento e transformação.

Vázquez $^{14}$, assim como Gramsci, considera que o homem comum não compreende que seus atos práticos contribuem "para escrever a história humana". Por sua vez, a filosofia da práxis, vincula "práxis e revolução, isto é, a prática produtiva (transformação da natureza mediante o trabalho humano) com a prática revolucionária (transformação da sociedade

\footnotetext{
${ }^{13}$ Ibid., p. $21 ; 145$.

${ }^{14}$ Ibid., p. 15; 37.
} 
mediante a ação dos homens), como duas formas inseparáveis da práxis total social".

O trabalho passa a ser compreendido enquanto expressão e produção, enfim, ação do homem no mundo que também se circunscreve no âmbito da apropriação e da produção cultural. A práxis insere-se, portanto, como forma de distinguir a ação consciente do homem da ação do homem prático, que termina por traduzir-se em uma ação alienada.

Vale salientar que o homem comum não vive em um mundo ateórico. Entretanto, sinaliza Gramsci (1995, p. 147), "referir-se ao senso comum como prova de verdade é um contra-senso", uma vez que a forma como sua consciência, e consequentemente os seus atos (individuais), tem sido formada determinam uma concepção de mundo que o afasta de uma práxis revolucionária.

A práxis social, para os marxistas, implica um "grau de homogeneidade, de autoconsciência e de organização" das classes perante o Estado. Em Marx (1978, p. 129-130) esse é o momento em que se reconhece na "estrutura econômica da sociedade, a base real sobre a qual se levanta uma superestrutura jurídica e política, e à qual correspondem formas sociais determinadas de consciência".

Em Gramsci, afirma Buci-Glucksmann (1990, p. 124-125), esse momento relaciona-se, inicialmente, à passagem do momento econômico (o reconhecimento das condições matérias de sua ação) para o ético-político (elaboração superior da infra-estrutura em superestrutura complexa na consciência dos homens); e, posteriormente, ao atingimento da hegemonia, ou seja, "a relação integral entre classe/Estado/sociedade".

Gramsci (1995, p. 22), ao tratar da cultura como crítica da civilização (civiltà) e da consciência de classe do proletariado, enfatiza tanto o valor gnosiológico da filosofia do marxismo e "a importância e o significado que têm os partidos políticos, no mundo moderno: os partidos 
são "a pedra-de-toque da unificação de teoria e prática, entendida como processo histórico real" ${ }^{15}$.

Portanto, todo movimento cultural que pretenda substituir o senso comum e as velhas concepções do mundo e construir uma nova "ordem intelectual", segundo Gramsci (1995, p. 27), deve trabalhar vastas camadas populares na luta por uma filosofia de massa capaz de fazer de cada homem um intelectual e na criação de "elites de intelectuais de novo tipo, que surjam diretamente da massa e que permaneçam em contato com ela para tornarem-se os seus sustentáculos".

A análise de Gramsci sobre a formação de intelectuais de novo tipo coaduna-se à III ${ }^{\mathrm{a}}$ tese de Marx sobre Feuerbach (1978, p. 51): "a doutrina materialista sobre a mudança das contingências e da educação se esquece de que tais contingências são mudadas pelos homens e que o próprio educador deve ser educado".

Em sua militância política, Gramsci, segundo Manacorda (1990, p. 183), fez da atividade educativa um compromisso constante, denunciando o caráter classista da escola que, em seu esquema dualista, reflete a divisão social: uma escola elementar e profissional para o povo e uma escola clássica para as classes dirigentes; e reconhecendo "a conformidade histórica entre a formação humanística e as exigências da formação do intelectual tradicional".

Na prisão, Gramsci (1991, p. 128) vivencia algumas experiências educacionais que o mantêm dividido em relação a duas opções pedagógicas: o espontaneísmo e o voluntarismo. Entretanto, ao analisar o desenvolvimento intelectual do filho Délio (cinco anos), define que a espontaneidade deve limitar-se à primeira infância sem, contudo, cair em uma idolatria em relação à criança ("puerocentrismo"), mas "adequar-se a suas novas possibilidades lógicas e forçá-las o quanto possível" (MANACORDA, 1990, p. 71-73).

\footnotetext{
${ }^{15}$ Apesar tecer várias críticas aos partidos e afirmar a importância dos Conselhos de fábrica na formação da consciência política do proletariado. A esse respeito ver Manacorda (1990, p. 189).
} 
Gramsci, segundo Manacorda ${ }^{16}$, "capta perfeitamente a contradição do espontaneísmo" da pedagogia idealista, em que a exaltação da espontaneidade, o "respeito pela criança", traduz-se, na prática, na "renúncia a educar", no "abandono completo da criança ao autoritarismo, ou seja, à pressão exercida objetivamente pelo ambiente".

Gramsci (1991, p. 212) também rejeita a "estadolatria" e escreve à esposa alertando que ela, enquanto elemento do Estado, tem o dever de "representar e exercer o poder de coerção, em determinadas esferas, para modificar molecularmente a sociedade e em especial para tornar a geração nascente preparada para a nova vida", ou seja, "de praticar em determinada esfera aquelas ações que o Estado pratica de modo concentrado sobre toda a área social".

Segundo Manacorda (1990, p. 221), “o paradoxo (se podemos dizer assim) da pedagogia gramsciana" está em que "a personalidade faz-se tanto mais livre e mais rica, quanto mais, subtraída aos influxos casuais do ambiente, é obrigada a disciplinar-se; a liberdade individual é tanto mais ampla e real, quanto mais o indivíduo age como elemento do Estado".

Gramsci $(1989$, p. 121; 132; 136) atribui à sociedade, a separação entre vida produtiva e vida política, as razões da aparente crise escolar e reivindica, para o mundo moderno, uma "escola unitária ou de formação humanista (entendido este termo, "humanismo", em sentido amplo e não apenas em sentido tradicional) ou de cultura geral", entendida como capacidade de pensar e estudar e de "dirigir ou de controlar a quem dirige".

Para o materialismo histórico e dialético, a história do homem é a história da produção da própria cultura (produção de bens materiais e espirituais). Com a divisão do trabalho e o surgimento das classes sociais, o homem em vez de apropriar-se da cultura, de produzi-la, pode vir a alienarse dela, transformando-a em uma realidade acima dele, reificando-a, ocorrendo o processo de alienação.

A cultura deixa de ser um bem consumido e produzido por todos (propriedade comum do grupo) para tornar-se privilégio de alguns, deixa de

${ }^{16}$ Ibid., p. 74-75. 
ser um bem coletivo e passa a não estar à disposição de todos. Por ser um processo histórico, conclui Vieira Pinto (1994, p. 40): "nas sociedades divididas em classes, a cultura tem necessariamente base de classe".

Gramsci (1989, p. 124) procura romper com o caráter classista da escola e propõe dois níveis na escola unitária: no primeiro, na "escola ativa" (não de tipo libertária), busca-se disciplinar, atingir uma "coletivização" do tipo social; no segundo, na escola criadora, busca-se "criar os valores fundamentais do 'humanismo', a auto-disciplina intelectual e a autonomia moral" necessários a uma posterior preparação "de caráter científico (estudo universitário)" ou "de caráter imediatamente prático-produtivo (indústria, burocracia, organização de trocas etc.)".

A fase criadora indica "um método de investigação e de conhecimento", indica "que a aprendizagem corre notadamente graças a um esforço espontâneo e autônomo do discente, e no qual o professor exerce apenas uma função de guia amigável, como ocorre ou deveria ocorrer na universidade". A escola unitária é “o início de novas relações entre o trabalho intelectual e o trabalho industrial, não apenas na escola, mas em toda a vida social". De forma que "o princípio unitário [...] refletir-se-á em todos os organismos de cultura, transformando-os e emprestando-lhes um novo conteúdo" (GRAMSCI, 1989, p. 124-125).

Gramsci propõe, enfatiza Manacorda (1990, p. 163-164), a "escola unitária, na base, e academias e universidades, no vértice", buscando evitar o salto de continuidade entre eles. A academia, seguindo o modelo dos círculos e das associações, seria "a forma de organização cultural para aqueles que, após a escola unitária, passarão à atividade profissional", e manterá a colaboração com "as universidades e as escolas superiores especializadas" de modo a "dar um impulso inaudito à cultura em todo o território nacional"

A esse respeito, Gramsci $(1989$, p. 125; 137) denuncia a independência entre universidade e academia, consequência da separação "entre a alta cultura e a vida, entre os intelectuais e o povo", e também a preocupação da escola "profissional” em "satisfazer interesses práticos 
imediatos". Esse tipo de escola para o povo, apesar de "louvada como democrática", "não tende mais nem sequer a conservar a ilusão" de que, para além da mera qualificação, “cada 'cidadão' possa se tornar 'governante". Primícias de uma democracia política!

A ampliação do Estado e de seus aparelhos, como a escola, em Gramsci ${ }^{17}$, conduz a propostas de ampliação da função do Estado no campo da educação: fixação da idade escolar obrigatória, construção de edificações apropriadas, investimento em material didático, ampliação e preparação do corpo docente, medidas necessárias à eficiência da escola; assim como, ampliação do orçamento com a educação nacional e a função pública da educação, de forma a "envolver todas as gerações, sem divisões de grupos ou de castas".

Vale salientar que Gramsci não compreende o professor como elemento individual, destaca Manacorda (1990, p. 97, 246), mas como "conjunto dos elementos do estado [sic] destinados a educar as jovens gerações", consciente da situação objetiva que envolve o corpo docente e tentando superar qualquer "atitude individualista na consideração da relação educacional".

Nesse sentido, afirma Gramsci (1989, p. 131), o encontro entre escola e vida "somente pode ser representado pelo trabalho vivo do professor, na medida em que o mestre é consciente [tanto] dos contrastes entre o tipo de sociedade e de cultura que ele representa e o tipo de sociedade e de cultura representado pelos alunos", quanto "de sua tarefa, que consiste em acelerar e em disciplinar a formação da criança conforme o tipo superior em luta com o tipo inferior".

\section{As contradições constitutivas do fazer pedagógico}

O contado com a contradição possibilita compreender o caráter provisório e superável do real. Portanto, trabalhar as contradições do fazer pedagógico implica apontar o caráter contraditório e provisório na e da

${ }^{17}$ Ibid., p. 121. 
prática pedagógica, construída nesse real, e a possibilidade de sua superação. A contradição possibilita que as formações materiais, entre elas, as concepções do mundo e, por conseguinte, a concepção do professor, passem de um estágio do desenvolvimento a outro.

Há uma unidade entre os contrários que implica uma coexistência, dado que um não pode existir sem o outro, e uma identidade, uma vez que, por fazerem parte de uma única essência, os contrários coincidem. Entretanto, essa identidade é temporária e relativa. Nesse sentido, uma vez compreendida a origem das contradições, enfrentadas e superadas, chega-se a um novo estado qualitativo que inclui novas contradições, em um eterno devenir.

Nesse sentido, dentre as contradições do fazer educativo pode-se citar: o professor e o político; a teoria e a prática; a universidade e a escola; o desenvolvimento e a aprendizagem; que se encontram dialeticamente relacionadas. Essas contradições precisam ser necessariamente revisitadas e a sua superação proposta.

\section{O político e o professor}

A aproximação do professor com a sua prática, ou melhor, a sua imersão na vida cotidiana, impede-o de compreender a relevância ou a importância política do seu papel na sociedade, ou seja, o de manutenção ou transformação do status quo.

Entretanto, o homem é, antes de tudo, um ser político, no sentido de que as suas escolhas e o seu comportamento traduzem uma concepção do mundo construída nas relações estabelecidas ao longo de sua vida. Portanto, separar a profissão da vida é o mesmo que separar o homem da sociedade, o homem da ciência, é pensar um mundo em que os indivíduos se desenvolvessem e, outro mundo, em que esse indivíduo entraria apenas fortuitamente em contato, o mundo político, o mundo do trabalho, o mundo da profissão, entre outros. 
Essa concepção coaduna-se à concepção de exterioridade do mundo a que o homem moderno encontra-se subjugado. Entretanto, o homem é constituído em uma determinada sociedade, ele é um ser social e, portanto, político, e é nesse e através desse contexto em que ele se desenvolve que o próprio trabalho docente se define.

O ser professor surge, portanto, do ser social, do ser político, e não ao contrário. Entretanto, a prática e a concepção desse ser professor irão redefinir a prática e a concepção, enfim, os caminhos do ser social.

\section{A prática e a teoria}

O processo de humanização encontra-se dialeticamente vinculado à relação teoria e prática, uma vez que através da prática social o homem tem produzido cultura e, consequentemente, a si mesmo, objetivando-se. Essa objetivação gera novas necessidades e a produção de novas objetivações, novas idéias e novas ações.

Entretanto, historicamente, essa relação tem sido tratada de forma dicotômica, ora distanciando a teoria da prática, separando o pensar do agir, ora subordinando a prática à teoria, assim, a realidade estática e a-histórica é analisada a partir de um conhecimento anterior já dado e estabelecido.

A constituição do professor, enquanto sujeito social, vincula-se à compreensão acerca dessa relação. A sua objetivação implica uma reflexão crítica acerca do papel que desenvolve no processo educativo, que, por conseguinte, implica tanto a aproximação teoria e prática, questionando os seus pressupostos, quanto o enfrentamento da reificação da teoria e da prática.

Nesse sentido, torna-se imprescindível que o professor se aproprie das ferramentas necessárias à compreensão de que a prática pedagógica, enquanto relação de hegemonia, encontra-se inserida em um determinado projeto de educação, determinado por uma dada sociedade.

A teoria e a prática passam a ser compreendidas como construção humana e não como algo já pronto, tornando possível pensar a construção 
de uma nova educação voltada para uma nova sociedade, mesmo que dentro de certos limites.

A Universidade é, portanto, um dos espaços dessa aproximação e desse enfrentamento, de forma a favorecer o pensar filosófico, porque nascido da reflexão crítica sobre sua própria prática, sobre os problemas éticos, jurídicos, religiosos e morais, que possibilitam a reunificação entre teoria e prática. Entretanto, considerando as contradições que permeiam, a Universidade tem favorecido um reducionismo e um revisionismo que se convertem em um esvaziamento da própria teoria.

A prática mostra que essas contradições têm aberto espaços para trabalhar uma concepção que promova a emancipação social e humana. $\mathrm{Na}$ última década, a Universidade Federal da Paraíba tem buscado a reformulação curricular de seus cursos com o intuito de introduzir o contato com a realidade profissional, ao longo do curso ${ }^{18}$. Entretanto, esse processo tem sido atravessado pela dificuldade de admissão dessa inserção após séculos de submissão da prática à teoria.

\section{A escola e a universidade}

A relação escola e Universidade tem se pautado pela intervenção da Universidade, enquanto detentora de saberes, na escola. Entretanto, a escola, em especial, as escolas públicas são campos privilegiados para se trabalhar as contradições da e na sociedade capitalista e em suas instituições, visando à superação da situação de classe da qual são um reflexo.

Ainda que o professor que leciona em escola pública, seja ex-aluno dessa escola, há uma distância entre o ex-aluno e o atual professor tanto espaciais, quanto de perspectiva e posição frente a essa instituição e ao seu papel. O tempo e a ideologia dominante, veiculada pela e na escola, durante os anos escolares, se encarregaram de "lapidar" a concepção do mundo

\footnotetext{
${ }^{18}$ Resolução UFPB/CONSEPE nº 04/2004, estabelece que a Prática Curricular e o Estágio Supervisionado de Ensino constituem a Base Curricular para os Cursos de Licenciatura e devem ser oferecidos ao longo do curso, como observação e interlocução com a realidade, como aprofundamento teórico-metodológico da práxis docente e como iniciação e intervenção profissional acompanhada.
} 
desses sujeitos de forma a afastá-lo cada vez mais das expectativas e necessidades de seu grupo social, cabendo à Universidade o golpe final: transformá-lo em “doutor”.

A partir daí, a perspectiva ao retornar à escola segue outros caminhos. Não é mais o aluno que pertencia àquela determinada classe ou grupo social, agora é o professor, acompanhado de novos olhares, expectativas e necessidades, de novas formas de se vestir, de se comportar, de falar. Assim, se como ex-aluno ele pôde, todos podem. E viva a democracia e a meritocracia!

Entretanto, essa relação entre o professor oriundo da camada popular e a escola não é tranquila, mas atravessada pela contradição entre o ser social desses sujeitos e a sua posição nos aparelhos de hegemonia, no caso, na escola. A contradição é resolvida com aconselhamento, com rejeição ao aluno ou se identificando com a realidade do grupo social a que pertenceu.

O contato permanente com a escola, e as contradições que a permeiam, possibilita que a Universidade venha a ser espaço de reflexão teórica e de propostas que, nascidas da prática, a tornem instrumento de emancipação humana e social. Entretanto, onde encontrar na Universidade a reflexão, ou onde encontrar a Universidade da reflexão sobre as escolas reais?

A resposta a essa questão encontra-se nos espaços em que a Universidade se mantém ligada à vida, ou seja, a prática e os estágios, oferecidos ao longo do Curso, a extensão, a pesquisa e o ensino que eles suscitam, de forma que "a teoria [emirja] molhada da prática vivida" (FREIRE, 2004, p. 32).

\section{A aprendizagem e o desenvolvimento}

O discurso corrente e pretensamente neutro sobre a importância da educação no desenvolvimento dos indivíduos traz implicitamente a concepção de que são as idéias que criam a realidade social, e não a realidade social que cria a consciência. Realidade que, na maioria das vezes, 
se restringe à realidade sócio-econômica do aluno ${ }^{19}$ e possui uma conotação negativa.

Assim, a aprendizagem é possível pelo desenvolvimento do intelecto do indivíduo, das idéias, como em Hegel e no idealismo; e não pelos elementos trazidos a partir da sua inserção na prática social, na realidade, como no materialismo.

Mesmo que o professor, principalmente da escola pública, compreenda, a partir do desenvolvimento da prática pedagógica, que a aprendizagem significa a diferença no desenvolvimento da camada social atendida pela escola pública, faltam-lhe elementos teórico-práticos que o habilite nessa apreensão.

Portanto, pode-se afirmar que a formação pedagógica desvinculada da prática implica uma leitura fragmentada e contraditória da teoria e da própria realidade. Essa concepção fragmentada, aliada às demais contradições, impossibilita o professor de elaborar de forma unitária sua compreensão acerca da relação desenvolvimento e aprendizagem, do processo educativo, enfim, da relação educação e sociedade.

Nesse sentido, ao destacar a aprendizagem, busca-se situar a importância do ensino, da realidade, da prática para o desenvolvimento, uma vez que o aprendizado, enquanto processo de apropriação e produção da cultura, propicia a objetivação do homem o seu desenvolvimento.

Gramsci chama a atenção para a importância da relação pedagógica que, no âmbito escolar não significa criar tão somente condições materiais, mas condições que propiciem a leitura crítica e a tomada de consciência de sua própria realidade. A relação entre o professor e o aluno torna-se, portanto, mediadora do processo educativo, do processo de apropriação da cultura historicamente elaborada.

\footnotetext{
${ }^{19}$ Historicamente, compreende-se que a psicologia deu um salto qualitativo, ao passar de uma análise individualista de seu objeto de estudo a uma análise social. Entretanto, ainda percebe-se que essa análise, na maioria das vezes, "mascara" a análise histórica. Se, a análise individual negligencia o aspecto social, reduzindo diferenças sociais a diferenças individuais; a análise social parece reduzir as questões históricas ao meio social mais próximo ao sujeito, ou seja, à família, à escola, ao bairro, ao que denomino "individualização do social".
} 
Nessa perspectiva, o professor tem como papel possibilitar que o desenvolvimento vá além de suas possibilidades imediatas, compreendendo que os limites dessa ação que não se restringe e nem tem a sua origem no espaço escolar, mas nos condicionantes sociais.

A função do professor é a de organizador, no sentido gramsciano de intelectual, e o seu papel é colocar-se como sujeito social em relação com outro sujeito social, para que a personalidade possa ser desenvolvida. A esse respeito, Vigotski (2000, p. 35) ressalta que "a personalidade = um agregado de relações sociais. [...] é o conjunto das relações sociais. As funções psíquicas superiores criam-se no coletivo".

Nesse sentido, ao se inverter a expressão desenvolvimento e aprendizagem para aprendizagem e desenvolvimento, não se está negando a importância do desenvolvimento no processo de aprendizado, mas enfatizando a determinação da realidade social na consciência, determinação essa na qual o professor, enquanto elemento do Estado, tem o seu papel.

\section{A práxis como superação das contradições constitutivas do fazer educativo}

A compreensão acerca da contradição do real, que tem origem na divisão social do trabalho e no processo de desenvolvimento humano, favorece a consciência crítica e a emancipação humana, bem como a busca de transformação política, social e econômica. A consciência da contradição do real, através da práxis, é “o momento em que a contradição se torna princípio explicativo do real" (CURY, 1986, p. 32).

A educação, na perspectiva gramsciana, é trabalho efetivo, ação positiva do homem, assim como é consciência positiva, humana, ou seja, práxis. A práxis é o momento da emancipação humana e social, momento efetivo e necessário para a formação, através da prática social, de uma nova concepção do mundo mais unitária e autônoma em todos os aspectos de sua existência. 
A práxis, enquanto "atividade essencial" de produção da humanidade, enquanto compreensão da prática social humana insere-se, portanto, como forma de distinguir a ação do homem consciente e crítico da ação do homem prático, que se traduz em uma ação alienada.

Nesse sentido, a práxis é a condição pedagógica necessária para que a contradição do real, que se reflete da e na prática e da e na concepção do professor possa ser trabalhada, ainda que dentro de certos limites. Por um lado, compreendendo a relação educação e sociedade e, nessa relação, o seu papel de possibilitar ao aluno ascender ao gênero humano e, por outro lado, a sua função na emancipação humana e social. Enfim, uma luta cultural e, consequentemente, uma tomada de consciência.

Uma luta cultural, uma reforma intelectual e moral, necessária ao abalamento das "fortificações" das sociedades capitalistas e à compreensão da relação educação e sociedade e do professor como elemento do Estado (intelectual), que tem como função organizar a hegemonia de um grupo, combatendo o senso comum e definindo a própria filosofia, a filosofia da práxis.

Uma tomada de consciência, um complexo processo psicológico interior em que a apropriação da cultura possibilita a transformação e a elevação da concepção do mundo anterior, que tem o seu acento na prática. Um processo de aprendizagem em que o papel do professor é levar o aluno, enquanto ser social, a atingir níveis mais altos de desenvolvimento.

Entretanto, essa luta cultural e essa tomada de consciência só podem vir a se realizar através da filosofia da práxis que possibilita tanto a passagem do momento econômico para o ético-político, como a compreender a(s) filosofia(s) implícita(s) nas propostas pedagógicas veiculadas pelo Estado na escola, aparelho de Estado, e no fazer do professor, intelectual coletivo e elemento do Estado. Como afirma Gramsci (1995, p. 18), não se trata “de introduzir ex novo uma ciência na vida individual de 'todos', mas de inovar e tornar 'crítica' uma atividade já existente", uma vez que o homem não vive em um mundo a-teórico. 
Ao propor a transformação política, social e econômica, e a construção de uma nova sociedade (ou de uma nova organização social), não cabe, portanto, tratar de uma ação em si mesma, desprovida de conteúdo ideológico, mas de uma ação específica, em um contexto histórico, em relação a um objetivo ou a um fim que se pretenda alcançar. Nesse sentido, pergunta-se: a práxis estaria circunscrita aos movimentos sociais e à educação informal?

A resposta a essa pergunta é negativa, uma vez que a Universidade, enquanto espaço de contradição, pode possibilitar novos olhares, novos sentimentos, novos pensares, novas necessidades e novas ações, uma nova práxis, que aliada ao engajamento do professor em associações de classe, cursos e reuniões pedagógicas, assim como ao conhecimento da matéria e à forma de ensiná-la, une o político ao educacional no enfrentamento das questões que permeiam a educação.

\section{Referências bibliográficas}

ANDERSON, Perry. As antinomias de Antonio Gramsci. In: ANDERSON, Perry. et al. A estratégia revolucionária na atualidade. Tradução de Juarez Guimarães; Felix Sanches. São Paulo: Ed. Joruês, 1986. p. 7-74.

BAPTISTA, Maria das Graças de Almeida. A concepção do professor sobre sua função social: das práticas idealistas à possibilidade de uma ação crítica. 2008. $245 \mathrm{f}$. Tese (Doutorado em Educação) - Universidade Federal da Paraíba, João Pessoa, 2008.

BUCI-GLUCKSMANN, Christinne. Gramsci e o Estado: por uma teoria materialista da filosofia. Tradução de Angelina Peralva. 2. ed. Rio de Janeiro: Ed. Paz e Terra, 1990. 499 p. (Pensamento Crítico, v. 39).

CURY, Carlos Roberto Jamil. Educação e contradição. 2. ed. São Paulo: Ed. Cortez: Autores Associados, 1986. 133 p.

FREIRE, Paulo. Professora sim, tia não: cartas a quem ousa ensinar. 16. ed. São Paulo: Ed. Olho d'Água, 2004. 128 p.

GRAMSCI, Antonio. Cadernos do cárcere vol. 3. Maquiavel. Notas sobre o Estado e a política. Rio de Janeiro: Ed. Civilização Brasileira, 2000. 432 p.

GRAMSCI, Antonio. Concepscão dialética da História. Tradução de Carlos Nelson Coutinho. 10. ed. Rio de Janeiro: Ed. Civilização Brasileira, 1995. 341 p. 
GRAMSCI, Antonio. Cartas do Cárcere. 4. ed. Tradução de Noênio Spínola. Rio de Janeiro: Ed. Civilização Brasileira, 1991. 420 p.

GRAMSCI, Antonio. Os intelectuais e a organização da cultura. Tradução Carlos Nelson Coutinho. 7. ed. Rio de Janeiro: Ed. Civilização Brasileira, 1989. 244 p. (Perspectivas do homem. Série Filosofia, v. 48).

GRAMSCI E O BRASIL. Cronologia da vida. Reproduzido do vol. 1 dos Cadernos do cárcere, Rio de Janeiro, Ed. Civilização Brasileira, p. 49-74, 1999. Disponível em: <http://www.artnet.com.br/gramsci/arquiv115.htm> Acesso em: 25 ago. 2005.

JESUS, Antônio Tavares. O pensamento e a prática escolar de Gramsci. 2. ed. Campinas: Ed. Autores Associados, 2005. 129 p.

MANACORDA, Mario Alighiero. O princípio educativo em Gramsci. Tradução de William Lagos. Porto Alegre: Ed. Artes Médicas, 1990. 288p.

MARX, Karl. Teses contra Feuerbach. In: Marx. José Arthur Giannotti; Edgar Malagodi. 2. ed. São Paulo: Ed. Abril Cultural, 1978. p. 49-53. (Os Pensadores)

SIMIONATTOO, Ivete. O Brasil e as idéias de Gramsci. In: Gramsci: sua teoria, incidência no Brasil, influência no Serviço Social. 3. ed. São Paulo: Ed. Cortez, 2004. p. 93-172.

UNIVERSIDADE FEDERAL DA PARAÍBA. Resolução UFPB/CONSEPE $\mathbf{n}^{\mathbf{0}}$ 04/2004. Estabelece a Base Curricular, para a Formação Pedagógica dos Cursos de Licenciatura. Conselho Superior de Ensino, Pesquisa e Extensão da Universidade Federal da Paraíba, João Pessoa, 2004. Disponível em: <http://www.ufpb.br/sods/consepe/resolu/2004/Rsep042004.htm>. Acesso em: 14 jan. 2008.

VÁZQUEZ, Adolfo Sánchez. Filosofia da praxis. Tradução de Luiz Fernando Cardoso. Rio de Janeiro: Ed. Civilização Brasileira S.A., 1968. 454 p.

VIEIRA PINTO, Álvaro. A questão da universidade. 2. ed. São Paulo: Ed. Cortez, 1994. $102 \mathrm{p}$.

VIGOTSKI, Lev Semionovich. Manuscrito de 1929. Tradução de Alexandra Marenitch. In: SIRGADO, Angel Pino (Org.). Revista Educação e Sociedade: revista quadrimestral de Ciência da Educação, Campinas (SP): Ed. CEDES, n.71, p. 23-44, 2000. Versão inglesa de A. A. Puzyrei do original russo. 